\title{
$\Delta{ }^{9}$-Tetrahydrocannabivarin testing may not have the sensitivity to detect marijuana use among individuals ingesting dronabinol
}

\author{
Frances R. Levin ${ }^{1,2}$, John J. Mariani ${ }^{1,2}$, Daniel J. Brooks ${ }^{1}$, Shan $\mathrm{Xie}^{3}$, and Kathleen A. \\ Murray $^{2}$ \\ ${ }^{1}$ New York State Psychiatric Institute, Division on Substance Abuse, 1051 Riverside Drive, Unit \\ 120, New York, NY 10032, USA \\ 2 Department of Psychiatry, College of Physicians and Surgeons of Columbia University, 630 West \\ $168^{\text {th }}$ Street, New York, NY 10032, USA \\ ${ }^{3}$ Analytical Psychopharmacology Laboratory, Nathan Kline Institute for Psychiatric Research of \\ New York State, 140 Old Orangeburg Road, Orangeburg, NY 10962, USA
}

\begin{abstract}
The purpose of this study was to determine whether $\Delta^{9}$-tetrahydrocannabivarin (THCV), a plant cannabinoid, is a sensitive measure to detect recent marijuana use in cannabis dependent patients. It has been purported that smoking an illicit plant cannabis product will result in a positive THCV urinalysis, whereas the oral ingestion of therapeutic THC such as dronabinol will result in a negative THCV urinalysis, allowing for discrimination between pharmaceutical THC products and illicit marijuana products. In a double-blind placebo-controlled trial to determine the efficacy of dronabinol in cannabis dependence, all 117 patients produced a positive urine for the marijuana metabolite 11nor- $\Delta^{9}$-THC-9-carboxylic acid; THC-COOH, but $50 \%$ had an undetectable $(<1 \mathrm{ng} / \mathrm{ml})$ THCV$\mathrm{COOH}$ test. This suggests that THCV may not be a sensitive enough measure to detect recent marijuana use in all heavy marijuana users or that its absence may not discriminate between illicit marijuana use and oral ingestion of THC products such as dronabinol. We propose that the lack of THCV detection may be due to the variability of available cannabis strains smoked by marijuana users in community settings.
\end{abstract}

\section{Keywords \\ urinalysis; cannabis; dronabinol}

\section{Introduction}

Cannabis dependence is a serious condition that results in substantial occupational, medical, and psychiatric morbidity (D'Souza et al 2004; Stinson et al 2006). The primary active ingredient in marijuana, $\Delta^{9}$-tetrahydrocannabinol (THC), has been associated with dosedependent cognitive and motor impairment (Hunault et al 2008; Weinstein et al 2008). Large airway function impairment resulting in airflow obstruction and hyperinflation (Aldington et

\footnotetext{
Address correspondence to: Frances R. Levin, M.D., 1051 Riverside Drive, Unit 66, New York, New York 10032, U.S.A., Telephone: (212) 543-5896 FAX: (212) 543-6018, frl2@ columbia.edu.

Publisher's Disclaimer: This is a PDF file of an unedited manuscript that has been accepted for publication. As a service to our customers we are providing this early version of the manuscript. The manuscript will undergo copyediting, typesetting, and review of the resulting proof before it is published in its final citable form. Please note that during the production process errors may be discovered which could affect the content, and all legal disclaimers that apply to the journal pertain.
} 
al 2007), and neuropsychological deficits (Pope et al 2001) have also been associated with smoked marijuana. While recent epidemiologic surveys suggest that lifetime and past month use have decreased among both adolescents and adults (Monitoring the Future (MTF), 2008i National Survey on Drug Use and Health (NSDUH), 2009) the overall prevalence of cannabis dependence has not changed substantially (Compton et al 2004). Consistent with this, treatment admissions for cannabis dependence have increased by over $150 \%$ in the past fifteen years, with approximately $16 \%$ of all treatment admissions reporting marijuana as their primary drug of abuse Treatment Episode Data Set (TEDS), 2006.

Although there have been numerous studies assessing the efficacy of various psychosocial interventions for cannabis dependence (Budney et al 2006; Dennis et al 2004; Marihnana Treatment Project Research Group, 2004; Nordstrom and Levin 2007), there have only been a handful of outpatient pharmacotherapy trials (Carpenter et al 2009; Levin et al 2004; Tirado et al 2008). Most of the pharmacologic studies conducted have been laboratory studies utilizing nontreatment-seeking cannabis users (Hart 2005), limiting the generalizability of these findings to the outpatient treatment-seeking cannabis dependent population. To date, the medication that has shown the most promise is dronabinol, the international non-proprietary name for a pure isomer of THC, which is also a naturally occurring component of cannabis considered to be responsible for its main psychoactive effects. Several studies suggest that dronabinol may mitigate cannabis withdrawal symptoms and reduce the subjective effects of smoked marijuana (Budney et al 2007; Haney et al 2004; Hart et al 2002), although it did not reduce selfadministration of smoked marijuana in one laboratory study (Hart et al 2002). Furthermore, a recent laboratory study suggests that combining dronabinol with lofexidine, an alpha-2adrenergic receptor agonist approved in the United Kingdom to treat symptoms of opiate withdrawal, might be superior to dronabinol alone as a treatment for marijuana withdrawal and relapse (Haney et al 2008).

Given that dronabinol pharmacotherapy might be a clinically useful approach to reduce cannabis withdrawal symptoms and facilitate abstinence initiation and maintenance, investigation of this medication for treatment of cannabis dependence is underway. However, since ingestion of dronabinol produces a positive urine toxicology result for the THC metabolite, an objective method of distinguishing between smoked marijuana and oral THC administration would be clinically useful. One touted method has been to test for $\Delta^{9}$ tetrahydrocannabivarin (THCV), a naturally occurring cannabinoid that is found in various strains of marijuana but is not present in orally administered THC products (Elsohly and Slade 2005; Merkus 1971; Shoyama et al 1981).El Sohly et al. (1999) suggested that it might serve as a useful marker to distinguish the ingestion of cannabis from dronabinol. One study found that when four non-chronic marijuana users smoked one marijuana cigarette, THCV-COOH could be detected in the urine for up to two weeks. When these same participants were given dronabinol, THCV-COOH was not present (ElSohly et al 2001), suggesting that THCV-COOH detection could be utilized as a method to distinguish recent illicit marijuana use from therapeutic dronabinol ingestion in outpatient double-blind placebo-controlled randomized trials for dronabinol treatment of cannabis dependence. Here we report on the sensitivity of THCV in urine samples collected prior to study entry in the detection of heavy marijuana use in treatment-seeking cannabis dependent outpatients.

\section{Methods}

\subsection{Assessments}

One hundred and seventeen patients who enrolled in a double-blind placebo-controlled trial to assess the efficacy of dronabinol for the treatment of cannabis dependence were required to provide a urine sample prior to study entry. If the patient reported that he or she had used marijuana at least five times in the past week and if the urine sample was positive for the 
metabolite 11-nor- $\Delta^{9}$-tetrahydrocannabinol-9-carboxylic acid (THC-COOH), the patient was entered into the study. All urine samples were tested for 11-nor- $\Delta^{9}$-tetrahydrocannabivarin-9carboxylic acid (THCV-COOH). In addition, all urine samples were also tested for creatinine. As these patients had not yet received any medication, it was possible to compare THCV$\mathrm{COOH}$ urine results with quantitative THC-COOH urine levels without the confounding variable of dronabinol ingestion.

All laboratory testing was conducted at the Analytical Psychopharmacology Laboratory of the Nathan Kline Institute. THCV-COOH and THC-COOH concentrations were determined by gas chromatography-mass spectroscopy (GC-MS), operated in a negative chemical ionization (NCI) mode and using their deuterated derivatives as internal standards. A $15 \mathrm{~m}$ Rtx-5 Amine capillary column was programmed from $80^{\circ} \mathrm{C}$ (holding for $1 \mathrm{~min}$ ) to $280^{\circ} \mathrm{C}$ at increasing rate of $30^{\circ} \mathrm{C} / \mathrm{min}$. The target compounds and the internals were extracted with hexane-ethyl acetate (9:1) at $\mathrm{pH} 10$, and derivatized with trifluoroacetic anhydride and trifluoroethanol. The standard curves encompassed the range of $1-1000 \mathrm{ng} / \mathrm{ml}$ for both THCV-COOH and THC-COOH with the limit of quantification set at $1 \mathrm{ng} / \mathrm{ml}$. The coefficients of variation of inter- and intradays for both target compounds were $<7 \%$.

\subsection{Data Analysis}

The sensitivity of THCV-COOH in the detection of marijuana use was determined by calculating True Positive (number of samples with THCV-COOH detected)/True Positive (number of samples THCV-COOH detected) + False Negative (number of samples with no THCV-COOH detected). Looking at the sub-sample who had detectable THCV-COOH levels, the correlation between THC-COOH concentration and THCV-COOH concentration was determined using a Pearson Correlation. Secondary analysis was conducted using a linear regression model.

\section{Results}

Sample demographics are provided in Table 1 . Every baseline sample $(\mathrm{n}=117)$ was positive for THC-COOH. The mean THC-COOH concentration was $1724 \mathrm{ng} / \mathrm{ml}( \pm 2553)$. Conversely, only $50 \%(\mathrm{n}=58)$ of the samples had a detectable THCV-COOH level. The sensitivity for THCV-COOH was .496. For the samples that were detectable $(\geq 1 \mathrm{ng} / \mathrm{ml})$, the mean THCV$\mathrm{COOH}$ level was $4.40 \mathrm{ng} / \mathrm{ml}( \pm 3.87)$. Individuals with a detectable THCV-COOH level had a mean THC-COOH of $2705 \mathrm{ng} / \mathrm{ml}( \pm 3281)$ compared to the undetectable sample $(\mathrm{n}=59)$ that had a mean THC-COOH of $760 \mathrm{ng} / \mathrm{ml}( \pm 743)$. There was a significant correlation between THC-COOH and THCV-COOH levels $(\mathrm{r}=.446, \mathrm{p}<.01)$. The linear regression was also significant $(\beta=.446, \mathrm{t}=4.98, \mathrm{p}=.000)$. With every $1,000 \mathrm{ng} / \mathrm{ml}$ increase in THC-COOH there is an associated increase in the THCV-COOH by $1 \mathrm{ng} / \mathrm{ml}$. Figure 1 provides a scatter plot of these data.

\section{Discussion}

Based on previously published reports (ElSohly et al 1999; ElSohly et al 2001; Elsohly and Slade 2005), this study was designed so that GC-MS testing for THCV could be assessed for its ability to reliable detect illicit marijuana use in cannabis dependent outpatients. Because eligibility criteria required participants to have smoked marijuana at least five times in the week prior to study entry as part of a pattern of chronic cannabis dependence, we had the opportunity to assess the sensitivity of THCV to detect recent marijuana use in individuals who are regularly smoking "street" marijuana. Although there was a significant correlation between THC and THCV levels, THCV testing alone is not sensitive enough to detect all recent marijuana use. 
There are several explanations as to why the results of this study differ from those of previously published laboratory studies. THCV concentration varies considerably among different cannabis strains and in some naturally occurring strains may be entirely absent (Hillig and Mahlberg 2004; Small and Beckstead 1973). A related phenomenon has been described with THC content, which can vary considerably depending on a multitude of factors, such as the cultivated cannabis strain, location, climate, and light exposure of the harvested plant, and how much time has elapsed since the product was initially harvested (Licata et al 2005; Sifaneck et al 2007). Such factors may also affect the subjective quality of the drug (Chait and Pierri 1989). While THCV analysis of domestically available marijuana grown or seized in the United States is not available, it is likely that THCV content of the marijuana smoked by patients in New York City varies. Hillig and Mahlberg (2004) characterized quantitative and qualitative patterns of cannabinoid variations in various cannabis strains and found substantially higher levels of cannabidivarin (CBDV), either in the presence or absence of THCV, in Cannabis Indica compared to Cannabis Sativa.

Pertwee et al. (2008) reported that in studies with mice, $\Delta^{9}$ - THCV acted as a $\mathrm{CB}_{1}$ receptor antagonist at low doses and a $\mathrm{CB}_{1}$ receptor agonist at high doses. However, the relationship of the THCV doses studied to typical serum levels achieved by consuming cannabis available in the community is unknown. Therefore, while the available evidence suggests that THCV has potent interactions at the $\mathrm{CB} 1$ receptor its contribution to the psychoactive properties of cannabis are still not clearly understood. Hillig and Mahlberg (2004) observed that THCV was not present in many cannabis strains world-wide and posited a theory that humans may have selected against THCV in cannabis cultivation based on its cannabinoid receptor effects. The results reported in this study are consistent with those reported by Hillig and Mahlberg (2004); THCV is not present in a substantial proportion of cannabis available in the community. Further research is needed to better understand the role of THCV in producing cannabisinduced psychoactive effects, particularly whether its presence enhances or diminishes desirable subjective effects.

Since all published laboratory studies of THCV testing have used NIDA-grown marijuana and since all published data using NIDA marijuana have affirmed the presence of THCV, it is unquestionable that THCV is present in this strain. However, as suggested by the results of the present study, there may be substantial variability in the THCV content in cannabis cultivated and sold in the community and some domestically grown cannabis may contain minimal or no THCV at all. At present, it does not appear that THCV can be used as a reliable detection method of recent marijuana use since a negative test is not conclusive that there was no marijuana use. Nor can it be used as a reliable discriminatory method between illicitly smoked cannabis and therapeutic dronabinol ingestion. A corollary to this finding is that since there may be variability between NIDA-grown marijuana and marijuana available in the community, generalizing the results of laboratory research findings using NIDA-grown marijuana to the general population may have limitations.

\section{References}

Monitoring the Future, 2008. National Results on Adolescent Drug Use. 2008 [Accessed on June 15, 2009]. Available at: http://monitoringthefuture.org/pubs/monographs/overview2008.pdf

Aldington S, Williams M, Nowitz M, Weatherall M, Pritchard A, McNaughton A, Robinson G, Beasley R. Effects of cannabis on pulmonary structure, function and symptoms. Thorax 2007;62:1058-1063. [PubMed: 17666437]

Budney AJ, Moore BA, Rocha HL, Higgins ST. Clinical trial of abstinence-based vouchers and cognitivebehavioral therapy for cannabis dependence. J Consult Clin Psychol 2006;74:307-316. [PubMed: 16649875] 
Budney AJ, Vandrey RG, Hughes JR, Moore BA, Bahrenburg B. Oral delta-9-tetrahydrocannabinol suppresses cannabis withdrawal symptoms. Drug Alcohol Depend 2007;86:22-29. [PubMed: 16769180]

Carpenter KM, McDowell D, Brooks DJ, Cheng WY, Levin FR. A preliminary trial: double-blind comparison of nefazodone, bupropion-SR, and placebo in the treatment of cannabis dependence. Am J Addict 2009;18:53-64. [PubMed: 19219666]

Chait LD, Pierri J. Some physical characteristics of NIDA marijuana cigarettes. Addict Behav 1989;14:61-67. [PubMed: 2718825]

Compton WM, Grant BF, Colliver JD, Glantz MD, Stinson FS. Prevalence of marijuana use disorders in the United States: 1991-1992 and 2001-2002. Jama 2004;291:2114-2121. [PubMed: 15126440]

D’Souza DC, Perry E, MacDougall L, Ammerman Y, Cooper T, Wu YT, Braley G, Gueorguiova R, Krystal JH. The psychotomimetic effects of intravenous delta-9-tetrahydrocannabinol in healthy individuals: implications for psychosis. Neuropsychopharmacology 2004;29:1558-1572. [PubMed: 15173844]

Dennis M, Godley SH, Diamond G, Tims FM, Babor T, Donaldson J, Liddie H, Titus JC, Kaminer Y, Webb C, Hamilton N, Funk R. The Cannabis Youth Treatment (CYT) Study: main findings from two randomized trials. J Subst Abuse Treat 2004;27:197-213. [PubMed: 15501373]

ElSohly MA, Feng S, Murphy TP, Ross SA, Nimrod A, Mehmedic Z, Fortner N. Delta 9tetrahydrocannabivarin (delta 9-THCV) as a marker for the ingestion of cannabis versus Marinol. $\mathrm{J}$ Anal Toxicol 1999;23:222-224. [PubMed: 10369334]

ElSohly MA, Feng S, Murphy TP, Warrington AW, Ross S, Nimrod A, Mehmedic Z, Fortner N. Identification and quantitation of 11-nor-delta9-tetrahydrocannabivarin-9-carboxylic acid, a major metabolite of delta9-tetrahydrocannabivarin. J Anal Toxicol 2001;25:476-480. [PubMed: 11550824]

Elsohly MA, Slade D. Chemical constituents of marijuana: the complex mixture of natural cannabinoids. Life Sci 2005;78:539-548. [PubMed: 16199061]

Haney M, Hart CL, Vosburg SK, Comer SD, Reed SC, Foltin RW. Effects of THC and lofexidine in a human laboratory model of marijuana withdrawal and relapse. Psychopharmacology (Berl) 2008;197:157-168. [PubMed: 18161012]

Haney M, Hart CL, Vosburg SK, Nasser J, Bennett A, Zubaran C, Foltin RW. Marijuana withdrawal in humans: effects of oral THC or divalproex. Neuropsychopharmacology 2004;29:158-170. [PubMed: 14560320]

Hart CL. Increasing treatment options for cannabis dependence: a review of potential pharmacotherapies. Drug Alcohol Depend 2005;80:147-159. [PubMed: 15899556]

Hart CL, Haney M, Ward AS, Fischman MW, Foltin RW. Effects of oral THC maintenance on smoked marijuana self-administration. Drug Alcohol Depend 2002;67:301-309. [PubMed: 12127201]

Hillig K, Mahlberg P. A Chemotaxonomic Analysis of Cannabinoid Variation in Cannabis (Cannabaceae). Am J Botany 2004;91:966-975.

Hunault CC, Mensinga TT, Bocker KB, Schipper CM, Kruidenier M, Leenders ME, de Vries I, Meulenbelt J. Cognitive and psychomotor effects in males after smoking a combination of tobacco and cannabis containing up to $69 \mathrm{mg}$ delta-9-tetrahydrocannabinol (THC). Psychopharmacology (Berl). 2008

Levin FR, McDowell D, Evans SM, Nunes E, Akerele E, Donovan S, Vosburg SK. Pharmacotherapy for marijuana dependence: a double-blind, placebo-controlled pilot study of divalproex sodium. Am J Addict 2004;13:21-32. [PubMed: 14766435]

Licata M, Verri P, Beduschi G. Delta9 THC content in illicit cannabis products over the period 19972004 (first four months). Ann Ist Super Sanita 2005;41:483-485. [PubMed: 16569917]

Merkus FW. Cannabivarin and tetrahydrocannabivarin, two new constituents of hashish. Nature 1971;232:579-580. [PubMed: 4937510]

Marijuana Treatment Project Research Group. Brief treatments for cannabis dependence: Findings from a randomized multisite trial. J Consult Clin Psychol 2004;72:455-466. [PubMed: 15279529]

Nordstrom BR, Levin FR. Treatment of Cannabis Use Disorders: A Review of the Literature. American Journal on Addictions 2007;16:331-342. [PubMed: 17882603]

National Survey on Drug Use and Health, 2007. Results from the 2006 National Survey on Drug Use and Health: National Findings (Office of Applied Studies, NSDUH Series H-32, DHHS Publication 
No. SMA 07-4293). Rockville, MD: 2007 [Accessed on August 6, 2008]. Substance Abuse and Mental Health Services Administration. Available at: http://www.oas.samhsa.gov/nsduh/2k6nsduh/2k6Results.pdf

Pertwee RG. The diverse CB1 and CB2 receptor pharmacology of three plant cannabinoids: delta9tetrahydrocannabinol, cannabidiol and delta9-tetrahydrocannabivarin. Br J Pharmacol 2008;153:199-215. [PubMed: 17828291]

Pope HG Jr, Gruber AJ, Hudson JI, Huestis MA, Yurgelun-Todd D. Neuropsychological performance in long-term cannabis users. Archives of General Psychiatry 2001;58:909-915. [PubMed: 11576028]

Shoyama Y, Morimoto S, Nishioka I. Cannabis XIV. Two New Propyl Cannabinoids Cannabicyclovarin and ^7-cis-Iso-tetrahydrocannabivarin, from Thai Cannabis. Chem Pharm Bull 1981;29:3720.

Sifaneck SJ, Ream GL, Johnson BD, Dunlap E. Retail marijuana purchases in designer and commercial markets in New York City: sales units, weights, and prices per gram. Drug Alcohol Depend 2007;90 (Suppl 1):S40-51. [PubMed: 17055670]

Small E, Beckstead HD. Common cannabinoid phenotypes in 350 stocks of Cannabis. Lloydia 1973;36:144-165. [PubMed: 4744553]

Stinson FS, Ruan WJ, Pickering R, Grant BF. Cannabis use disorders in the USA: prevalence, correlates and co-morbidity. Psychol Med 2006;36:1447-1460. [PubMed: 16854249]

Treatment Episode Data Set, 2006. NIDA Infofacts: Marijuana, Treatment Episode Data Set (TEDS) Highlights. 2006 [Accessed on June 15, 2009]. available at: http://www.drugabuse.gov/Infofacts/treatmenttrends.html

Tirado CF, Goldman M, Lynch K, Kampman KM, Obrien CP. Atomoxetine for treatment of marijuana dependence: a report on the efficacy and high incidence of gastrointestinal adverse events in a pilot study. Drug Alcohol Depend 2008;94:254-257. [PubMed: 18182254]

Weinstein A, Brickner O, Lerman H, Greemland M, Bloch M, Lester H, Chisin R, Sarne Y, Mechoulam R, Bar-Hamburger R, Freedman N, Even-Sapir E. A study investigating the acute dose-response effects of $13 \mathrm{mg}$ and $17 \mathrm{mg}$ Delta 9- tetrahydrocannabinol on cognitive-motor skills, subjective and autonomic measures in regular users of marijuana. J Psychopharmacol 2008;22:441-451. [PubMed: 18635724] 


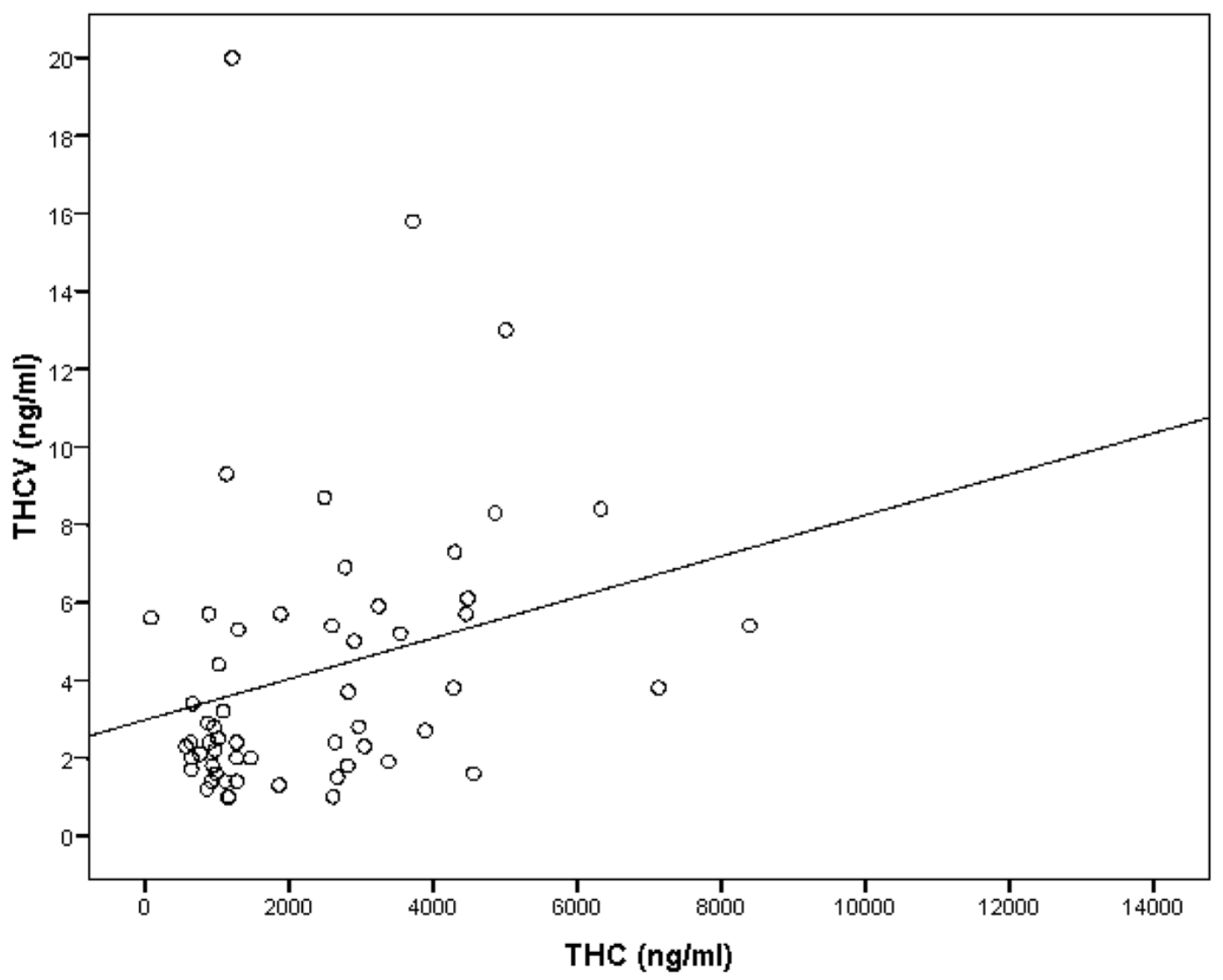

Figure 1.

Association between THCV-COOH levels and THC-COOH levels in marijuana using treatment seekers $(\mathrm{n}=58 ; \mathrm{r}=.446, \mathrm{p}<.01)$.

Note: There was an outlier ( $\mathrm{THC}-\mathrm{COOH}=23,380 \mathrm{ng} / \mathrm{ml}$ ) that was included in the analysis but was excluded from the graph because of scale reduction 
Table 1

Baseline Demographics

\begin{tabular}{|l|c|}
\hline \multicolumn{2}{|l|}{ N=117 } \\
\hline Demographics & $38.7 \pm 10.4$ \\
\hline Age (years) & $96(82 \%)$ \\
\hline Male & $25(21 \%)$ \\
\hline Race: African-American & $25(21 \%)$ \\
\hline Hispanic & $63(54 \%)$ \\
\hline Caucasian & $3(3 \%)$ \\
\hline Asian & $1(1 \%)$ \\
\hline Other & $14.4 \pm 2.6$ \\
\hline Education (years) & \\
\hline Pattern of Marijuana Use & $15.2 \pm 3.0$ \\
\hline Age $1^{\text {st } u s e ~(y e a r s) ~}$ & $18.4 \pm 5.0$ \\
\hline Age of Regular use (years) & $6.6 \pm 0.9$ \\
\hline Days used ( per week) & $5.4 \pm 8.0$ \\
\hline Amount used (joints per using day) & \\
\hline
\end{tabular}

